\title{
STREPTOCOCCUS INIAE OUTBREAKS IN BRAZILIAN NILE TILAPIA (OREOCHROMIS NILOTICUS L.) FARMS
}

\author{
H. C. P. Figueiredo*; L. Nobrega Netto; C. A. G. Leal; Ulisses P. Pereira; Glaúcia F. Mian.
}

AQUAVET- Laboratório de Doenças de Animais Aquáticos, Universidade Federal de Minas Gerais, Belo Horizonte, MG, Brasil.

Submitted: March 25, 2011; Returned to authors for corrections: August 02, 2011; Approved: January 16, 2012.

\begin{abstract}
This is the first report of outbreaks of Streptococcus iniae in Nile tilapia farms in South America. Seven isolates were identified by biochemical, serological and molecular tests. Their 16S rRNA gene sequences showed 100\% similarity with S. iniae ATCC 29178 and two distinct PFGE patterns were observed for Brazilian isolates.
\end{abstract}

Key words: Brazil, infection, MIC, PFGE, phylogenetic analysis, tilapia.

Streptococcosis is a major problem for fish production worldwide and it is associated with high economic losses. Currently, Streptococcus iniae (1), Streptococcus agalactiae (8), Streptococcus dysgalactiae (14), Streptococcus phocae (17), Streptococcus parauberis and Streptococcus ictaluri (2) have been described as pathogenic to fish.

Streptococcus iniae was first isolated from multifocal subcutaneous abscesses in captive Amazon freshwater dolphins, Inia geoffrensis (16). In fish, S. iniae infections are characterized by meningoencephalitis and septicemia that generally induce high morbidity and mortality rates. Disease outbreaks have been described in three distinct regions of the world: North America; the Middle East; and the Asia-Pacific (1). To date, only outbreaks of disease caused by $S$. agalactiae in Nile tilapia (Oreochromis niloticus L.) in commercial fish farms in Brazil were described (13). Thus, no description of $S$. iniae infection in fish was reported in the country until now.

The aim of this work was to describe outbreaks of $S$. iniae infection in Brazilian Nile tilapia farms, the sensibility of the isolates to florfenicol and to perform the genetic characterization of the strains.

Outbreaks of meningoencephalitis and septicemia were accompanied in two commercial Nile tilapia farms located in Paraná State, Brazil. These farms were located about $3 \mathrm{~km}$ apart on the same river. Fish (average weight of $800 \mathrm{~g}$ ) were reared in cages under high stock densities $\left(150 \mathrm{Kg} \mathrm{m}^{-3}\right)$. Inside the cages, the water temperature was approximately $30^{\circ} \mathrm{C}$ and dissolved oxygen showed concentration higher than $4 \mathrm{mg} \mathrm{L}^{-1}$. The main clinical signs observed were lethargy, erratic swimming, exophthalmia, skin darkness, and high mortality rates. Ten diseased fish from each farm were sampled, stored at $4{ }^{\circ} \mathrm{C}$, and immediately transported to the laboratory for bacteriological analysis.

Swabs of brain and kidney tissue from each fish were sampled aseptically, streaked onto 5\% sheep blood agar, and incubated at $28^{\circ} \mathrm{C}$ for $72 \mathrm{~h}$. The colonies obtained were tested by Gram stain, catalase and oxidase production and hemolysis. The isolates were further characterized phenotypically and

*Corresponding Author. Mailing address: AQUAVET- Laboratory of Aquatic Animal Diseases, Av. Antônio Carlos 6627, Pampulha, Belo Horizonte, MG, Brazil. 30.123970.; Tel.: +55 3134092126 Fax: +55 3134092080 ; E-mail: henrique@dmv.ufla.br 
serologically using API20 STREP and Slidex Latex Agglutination kits (both from BioMerieux, France), respectively.

The isolates were grown on sheep blood agar supplemented with $5 \%$ sheep blood for $48 \mathrm{~h}$ at $30{ }^{\circ} \mathrm{C}$. The colonies were collected, diluted in $180 \mu \mathrm{L}$ of lysis solution (20 $\mathrm{mg} \mathrm{ml}^{-1}$ lisozyme; $20 \mathrm{mM}$ Tris-HCl, $\mathrm{pH} 8.0 ; 2$ mM EDTA and $1.2 \%$ Triton $^{\circledR}$ ), and incubated at $37{ }^{\circ} \mathrm{C}$ for $1 \mathrm{~h}$. Total bacterial DNA was then extracted using the commercial kit QIAamp DNA mini kit (Qiagen) according to the manufacturer's instructions. To confirm the diagnosis, extracted DNA was used as a template in a $S$. iniae-specific PCR performed according to the procedure previously described by Mata et al. (12). In addition, 16S rRNA of three randomly selected strains (SI25-06, SI27-06 and SI29-06) were amplified by PCR with the universal primers $\mathrm{C} 70$ and B37 according to the method described by Fox et al. (10). After amplification, PCR products were purified using a Wizard PCR Preps kit (Promega) and sequenced. Sequencing reactions were performed using a BigDye $^{\mathrm{TM}}$ Terminator Cycle sequencing kit and run on an ABI 3730XL genetic analyzer (both from Applied Biosystems).

The phylogenetic relationship of the three isolates was determined by comparative $16 \mathrm{~S}$ rRNA gene sequence analysis. The sequences were aligned using CLUSTALW (23) with sequences of the following streptococcal species (available in the NCBI database): Streptococcus iniae ATCC 29178 (AF335572); Streptococcus parauberis (AY584477); Streptococcus phocae (AF235052); Streptococcus agalactiae (AB002479); Streptococcus dysgalactiae subsp. dysgalactiae (AB002485); Streptococcus dysgalactiae subsp. equisimilis (DQ232540); Streptococcus ictaluri (DQ462421); Streptococcus didelphis (AF176103); Streptococcus porcinus (AB002523); Streptococcus castoreus (AJ606047); and three fish strains of $S$. iniae, being two isolated from Nile tilapia, JW6 (GQ338314) and JW9 (GQ338315), and one from rainbow trout (Oncorhyncus mykiss) SF2 (FJ870987). The genetic distances matrix was obtained using Kimura's two- parameter model (11) and an evolutionary tree was created using the neighbor joining method (18) with Mega4 (22). Bootstrap values from 1000 replicates are displayed as percentages.

Restriction enzyme SmaI digests of genomic DNA of all isolates were analyzed by pulsed field gel electrophoresis (PFGE) as previously described by Oliveira et al. (15). Gel image were analyzed using Gel ComparII software ${ }^{\circledR}$ (Applied Maths) to make dendograms of the genetic relationships among the strains. The Dice coefficient (95\%) and unweighted pair group method with average linkages (UPGMA) was used for banding pattern and cluster analysis, respectively. The isolates that showed $100 \%$ similarity were considered indistinguishable and the isolates with similarity greater than $80 \%$ were considered clonally related (21).

Florfenicol susceptibility tests were conducted by broth microdilution and disk susceptibility methods according to the guidelines M42-A and M49-A, respectively, both established by the Clinical and Laboratory Standards Intitute $(3,4)$. The minimum inhibitory concentration (MIC) tests for florfenicol were performed using sterile dry microplates (Trek Diagnostic System) with the antibiotic concentration ranging from 0.06 to $64 \mu \mathrm{g} \mathrm{mL} \mathrm{m}^{-1}$. Escherichia coli ATCC 25922 was used as quality control for plates and procedures performed each day. All strains were tested in duplicate. The MIC was defined as the lowest concentration of antibiotic that prevented visible bacterial growth. Disk diffusion tests were performed on Mueller-Hinton agar (Difco), and with disks containing $30 \mu \mathrm{g}$ of florfenicol (Oxoid). Escherichia coli ATCC 25922 was used as quality control in all procedures. The diameters of the inhibition zones were measured with a ruler.

Gram-positive cocci were isolated from brain and kidney tissue of seven sick fish; five from farm A and two from farm B. These bacteria showed characteristic mucoid colonies with zones of $\beta$-haemolysis after 24 to $48 \mathrm{~h}$ incubation at $28{ }^{\circ} \mathrm{C}$ in ovine blood agar plates. Some colonies presented a double zone of haemolysis. None of the isolates could be serologically 
typed to any Lancefield group and in the API 20 Strep test inconclusive results were obtained. All isolates showed positive reactions in the $S$. iniae-specific PCR assay, generating amplicons of 870 bp confirming the bacterial identification. Computational analysis of $16 \mathrm{~S}$ rRNA sequences of Streptococcus iniae demonstrated that the Brazilian isolates are similar to each other and to reference strain ATCC 29178, showing a bootstrap percentage of $100 \%$. Figure 1 presents the phylogenetic tree of $S$. iniae isolates from Brazil, other fish isolates, the reference strain, and closely related species of streptococci.

The PFGE analysis showed three different patterns $\left(\mathrm{A}_{1}\right.$, $\mathrm{A}_{2}$, and $\mathrm{B}$ ) among the studied strains. The seven Brazilian strains belonged to the same pulse type shared in two subtypes $\left(\mathrm{A}_{1}\right.$ and $\left.\mathrm{A}_{2}\right)$ and $S$. iniae ATCC 29178 presented pattern $\mathrm{B}$. The groups $\mathrm{A}_{1}$ and $\mathrm{A}_{2}$ were clonally related, with $88 \%$ similarity according to the Dice coefficient (Figure 2). The $\mathrm{A}_{1}$ strains were isolated from both farms, whereas $\mathrm{A}_{2}$ strains occurred only on farm B. Additionally, both Brazilian S. iniae clusters showed 36\% similarity with pattern B of strain ATCC 29178 (Figure 2).

The distribution of the MIC values and the diameter of the inhibition zones of FLO against Escherichia coli ATCC 25922 ranged from 8 to $16 \mu \mathrm{g} \mathrm{mL}^{-1}$ and 24 to $30 \mathrm{~mm}$, respectively. In both cases, these values were in agreement with the acceptable ranges $(3,4)$. The diameter of inhibition zone and MIC values of FLO against $S$. iniae ranged from 1 to $8 \mu \mathrm{g} \mathrm{mL}^{-1}$ and 28 to $32 \mathrm{~mm}$, respectively. All strains were considered as susceptible to florfenicol by MIC and disk diffusion methods.

Currently, $S$. iniae is considered one of the most relevant streptococcal pathogen of cultured and wild fish $(20,5)$. While believing that this pathogen is distributed globally, before this study there is no report of its presence in Brazil, in contrast to other Gram-positive bacteria pathogenic to fish, such as $S$. agalactiae (13) and Lactococcus garvieae (9). Therefore, this study is the first report of disease outbreaks caused by $S$. iniae in Brazil.
In commercial fish farms, the main predisposing factors for $S$. iniae outbreaks are high stocking densities and high water temperatures; the disease usually occurs in adult fish (1, 19). Cages are the main culture system used for Nile tilapia production in Brazil. In this system, fish are reared under high stocking densities. Additionally, the outbreaks investigated in this study occurred during the summer and when fish reached the adult stage. These conditions were described as predisposing factors for outbreaks caused by $S$. agalactiae in Nile tilapia farms in Brazil (13), thus they seem to be common conditions associated with streptococcal infections in this fish species.

The seven strains presented to be clonally related in PFGE analysis Considering the close proximity of the two farms, it would be expected that both outbreaks should be due to a single clone; however, two different PFGE types were observed. This epidemiological condition may be associated with the simultaneous introduction of these two genetic variants at the same time or with a possible recent divergence from a common ancestor of some strains during persistent infections in fish from these farms. The PFGE of the Brazilian strains of $S$. iniae displayed only $36 \%$ genetic similarity with the pattern of $S$. iniae ATCC 29178. In a previous report from China, Zhou et al. (24) used PFGE typing with the restriction enzyme $\operatorname{SmaI}$ and found a minimal similarity score of $68.4 \%$ between 32 Chinese strains of $S$. iniae with the reference strain ATCC 29178. This finding might suggest that Brazilian and Chinese strains constitute two genetic clusters of low relatedness, however, additional analysis are requested to clear this issue.

The main treatment applied in cases of $S$. iniae outbreaks in fish farms is the oral administration of antibiotics. In Brazil, only florfenicol is approved for use in tilapia farms. Previous studies presented that florfenicol (7) and erythromycin (6) are very efficient in the treatment of $S$. iniae infections in sunshine bass (Morone chrysops x Morone saxatilis) and barramundi (Lates calcarifer), respectively. However, there is no in vitro 
data about florfenicol resistance pattern of fish isolates of $S$. iniae. Herein, we presented the first MIC values for $S$. iniae isolates against florfenicol.

The present work is the first report of phenotypic and genetic characterization of $S$. iniae isolated from outbreaks of meningoencephalitis and septicemia on Nile tilapia farms in Brazil. Moreover, two distinct genotypes of $S$. iniae are currently available in Brazil and all the strains were considered sensible to florfenicol.

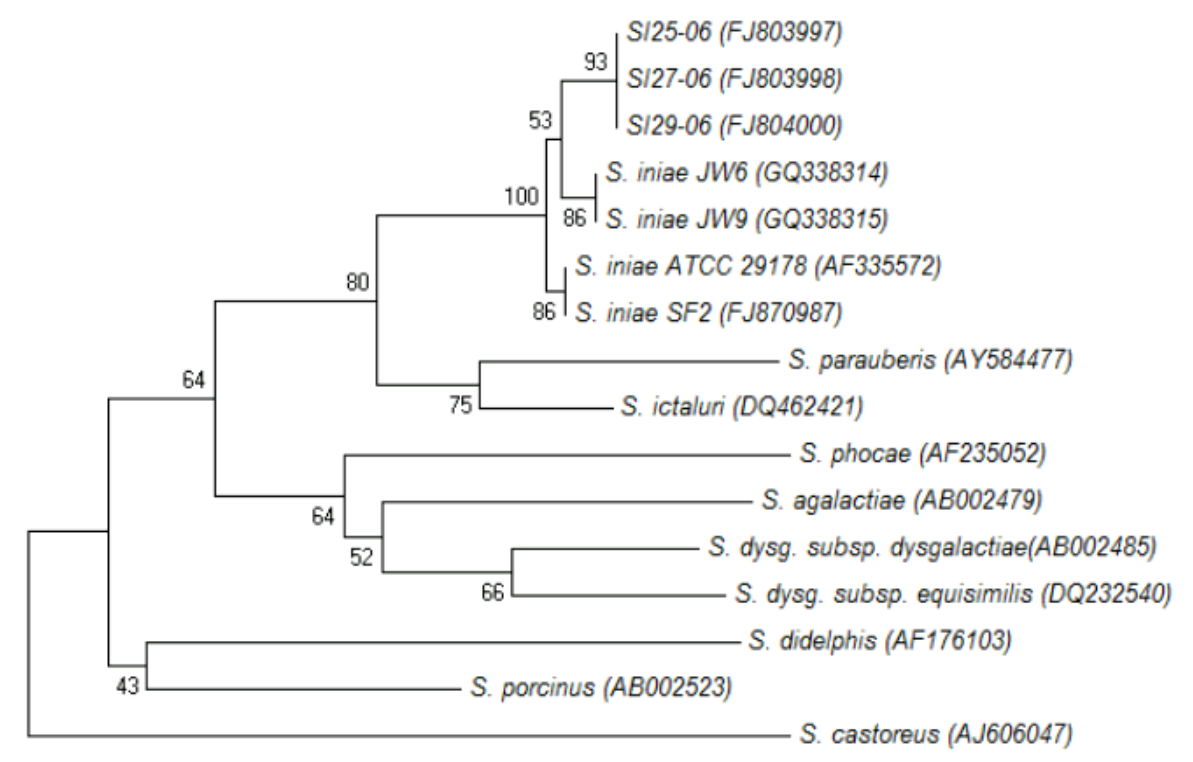

Figure 1. Neighbour-joining phylogenetic tree of 16S rRNA gene sequences of three Brazilian fish isolates (SI25-06, SI27-06 and SI2906), other fish strains of $S$. iniae and the most closely related species of streptococci. Bootstrap percentages (based on 1000 replications) are shown at branch points

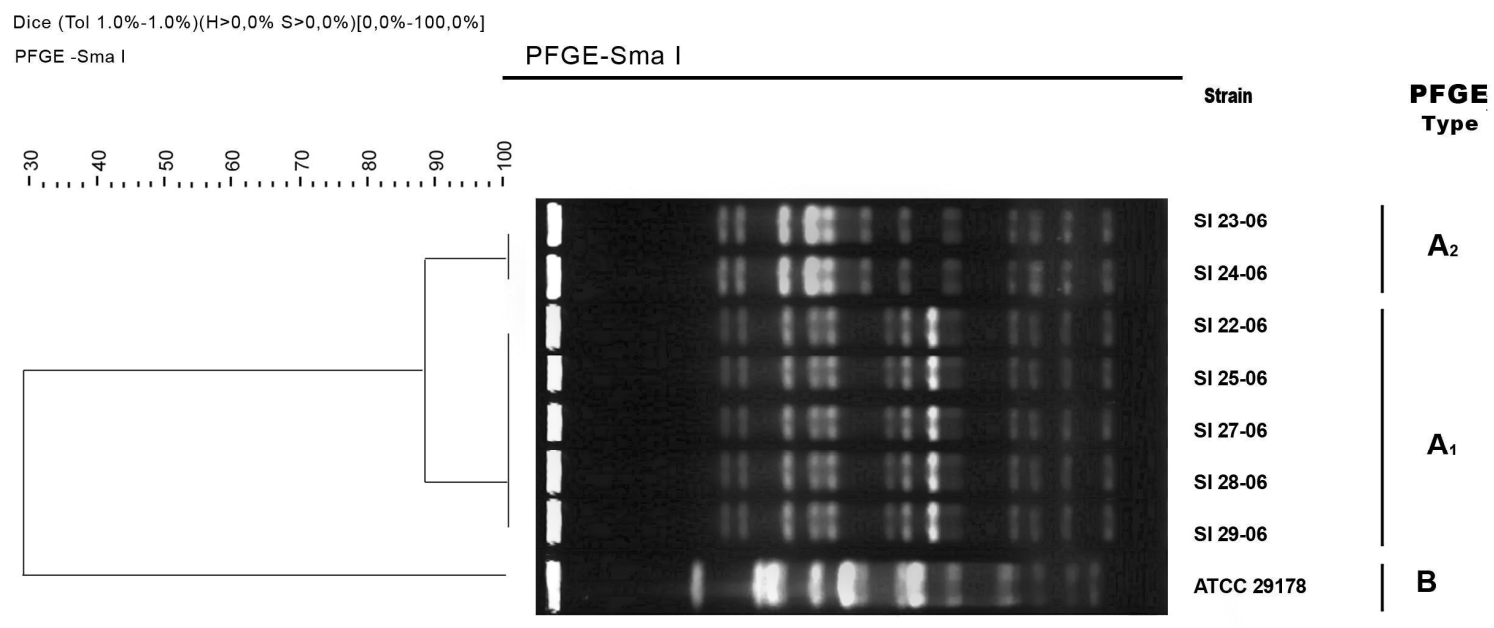

Figure 2. Dendogram constructed by similarity and clustering analyses using the Dice coefficient and UPGMA of digitized PFGE patterns for the seven isolates and S. iniae ATCC 29178 digested by Sma I. The code labels on the right of the figure represent the strains used in this study 


\section{ACKNOWLEDGEMENTS}

This work was supported by Grant FAPEMIG EDT 280505. We would like to thank CAPES and CNPq for the student fellowship and D. A. Custódio for technical assistance.

\section{REFERENCES}

1. Agnew, W.; Barnes, A.C. (2007). Streptococcus iniae: An aquatic pathogen of global veterinary significance and challenging candidate for reliable vaccination. Vet. Microbiol. 122, 1-15.

2. Camus, A.C.; Shewmaker, P.L.; Manuel, M.J.; Wise, D.J. (2008) Streptococcus ictaluri arthritis, osteolysis, myositis, and spinal meningitis in channel catfish broodstock. J. Aquat. Anim. Health 20, 54 62.

3. CLSI. (2006). Methods for broth dilution susceptibility testing of bacteria isolated from aquatic animals; Approved Guideline M49-A. Clinical and Laboratory Standards Institute, Wayne, Pennsylvania.

4. CLSI. (2006). Methods for antimicrobial disk susceptibility testing of bacteria isolated from aquatic animals; Approved Guideline M42-A. Clinical and Laboratory Standards Institute, Wayne, Pennsylvania.

5. Colorni, A.; Diamant, A.; Eldar, A.; Kvitt, H.; Zlotkin, A. (2002) Streptococcus iniae infection in red sea cage-cultured and wild fishes. Dis. Aquat. Org. 49, 165-170.

6. Creeper, J.H.; Buller, N.B. (2006). An outbreak of Streptococcus iniae in barramundi (Lates calcarifer) in freshwater cage culture. Aust. Vet. J. 84, $408-411$.

7. Darwish, A.M. (2007). Laboratory efficacy of florfenicol against Streptococcus iniae infection in sunshine bass. J. Aquat. Ani. Healt. 19, $1-7$.

8. Evans, J.J.; Klesius, P.H.; Gilbert, P.M.; Shoemaker, C.A.; Al Sarawi, M.A.; Landsberg, J.; Duremdez, R.; Al Marzouk, A.; Al Zenki, S. (2002). Characterization of B-haemolytic group B Streptococcus agalactiae in cultured seabream, Sparus auratus L., and wild mullet, Liza klunzingeri (Day), in Kuwait. J. Fish. Dis 25, 505-513.

9. Evans, J.J.; Klesius, P.H.; Shoemaker, C.A. (2009). First isolation and characterization of Lactococcus garvieae from Brazilian Nile tilapia, Oreochromis niloticus (L.), and pintado, Pseudoplathystoma corruscans (Spix \& Agassiz). J. Fish. Dis. 11, 943-51.

10. Fox, J.G.; Yan, L.L.; Dewhirst, F.E.; Paster, B.J.; Shames, B.; Murphy, J.C.; Hayward, A.; Belcher, J.C.; Mendes, E.N. (1995). Helicobacter bilis sp. nov., a novel Helicobacter species isolated from bile, livers, and intestines of aged, inbred mice. J. Clin. Microbiol. 33, 445-454.

11. Kimura, M. (1980). A simple method for estimating evolutionary rate of base substitutions through comparative studies of nucleotide sequences. J. Mol. Evol. 16, 111-120.

12. Mata, A.I.; Blanco, M.M.; Dominguez, L.; Fernandez-Garayzabal, J.F.; Gibello, A. (2004). Development of a PCR assay for Streptococcus iniae based on the lactase oxidase $(l c t O)$ gene with potencial diagnostic value. Vet. Microbiol. 101, 109-116.

13. Mian, G.F.; Godoy, D.T.; Leal, C.A.; Costa, G.M.; Figueiredo, H.C. (2009). Aspects of the natural history and virulence of S. agalactiae infection in Nile tilapia. Vet. Microbiol. 136,180-183.

14. Nomoto, R.; Munasinghe, L.I.; Jin, D.H.; Shimahara, Y.; Yasuda, H.; Nakamura, A.; Misawa, N.; Itami, T.; Yoshida, T. (2004). Lancefield group C Streptococcus dysgalactiae infection responsible for fish mortalities in Japan. J. Fish. Dis. 27, 679-686.

15. Oliveira, I.C.M.; Mattos, M.C.; Areal, M.F.T.; Ferreira-Carvalho, B.T.; Figueiredo, A.M.S.; Benchetrit, L.C. (2005). Pulsed-field gel electrophoresis of human group B streptococci isolated in Brazil. $J$. Chemotherapy. 17, 258-263.

16. Pier, G.B.; Madin, S.H. (1976). Streptococcus iniae sp. nov., beta hemolytic Streptococcus isolated from an amazon freshwater dolphin, Iniae geoffrensis. Int. J. Syst. Bacteriol. 26, 545-553.

17. Romalde, J.L.; Ravelo, C.; Valdés, I.; Magariños, B.; Fuente, E.; San Martín, C.; Avendaño Herrera, R.; Toranzo, A.E. (2008). Streptococcus phocae, an emerging pathogen for salmonid culture. Vet. Microbiol.130, 198-207.

18. Saitou, N.; Nei, M. (1987). The neighbor-joining method: A new method for reconstructing phylogenetic trees. Mol. Biol. Evol. 4, 406-425.

19. Shoemaker, C.A.; Evans, J.J.; Klesius, P.H. (2000). Density and dose: Factors affecting mortality of Streptococcus iniae infected tilapia (Oreochromis niloticus). Aquaculture 188, 229-235.

20. Shoemaker, C.A.; Klesius, P.H.; Evans, J.J. (2001). Prevalence of Streptococcus iniae in tilapia, hybrid striped bass, and channel catfish on commercial fish farms in the United States. Am. J. Vet. Res. 62, 174-177.

21. Singh, A.; Goering, R.V.; Simjee, S.; Foley, S.L.; Zervos, M.J. (2006). Application of molecular techniques to the study of hospital infection. Clin. Microbiol. Rev. 19, 512-530.

22. Tamura, K.; Dudley, J.; Nei, M.; Kumar, S. (2007). MEGA4: Molecular evolutionary genetics analysis (MEGA) software version 4.0. Mol. Biol. Evol. 24, 1596-1599.

23. Thompson, J.D.; Higgins, D.G.; Gibson, T.J. (1994). CLUSTAL W: Improving the sensitivity of progressive multiple sequence alignment through sequence weighting, position specific gap penalities and weight matrix choice. Nucleic Acids Res. 22, 4673-4680.

24. Zhou, S.M.; Xie, M.Q.; Zhu, X.Q.; Ma, Y.; Tan, Z.L.; Li, A.X. (2008). Identification and genetic characterization of Streptococcus iniae strains isolated from diseased fish in China. J. Fish. Dis. 31, 869-875. 